\title{
Antifungal Activity of Crude Extract from the Rhizome and Root of Smilacina japonica A. Gray
}

\author{
Wei Liu $\left(\mathbb{D},{ }^{1}\right.$ Baozheng Sun, ${ }^{1}$ Manman Yang,, Ziyue Zhang, ${ }^{1}$ Xiuxiu Zhang, \\ Tingsong Pang, ${ }^{1}$ and Shengzheng Wang $\mathbb{D D}^{2}$ \\ ${ }^{1}$ Faculty of Pharmacy, Shaanxi University of Science and Technology, Xi'an 710021, China \\ ${ }^{2}$ Department of Medicinal Chemistry, School of Pharmacy, Fourth Military Medical University, Xi'an 710032, China
}

Correspondence should be addressed to Wei Liu; liuweilw.happy@163.com and Shengzheng Wang; wangshengzheng001@163.com Received 7 March 2019; Accepted 1 July 2019; Published 15 July 2019

Academic Editor: Raffaele Capasso

Copyright (C) 2019 Wei Liu et al. This is an open access article distributed under the Creative Commons Attribution License, which permits unrestricted use, distribution, and reproduction in any medium, provided the original work is properly cited.

This study aimed to investigate the antifungal activity of hydroalcoholic extract from Smilacina japonica A. Gray (SJA) against different fungi. The minimum inhibitory concentration (MIC) for SJA was determined by the broth microdilution method. The antifungal effects of SJA against Candida albicans were further confirmed by cell growth test and time-kill curve test. The effects of SJA on the fungal morphology and ultrastructure were also evaluated. SJA has a broad-spectrum antifungal activity. The MICs of SJA against different fungi, including fluconazole-sensitive and -resistant Candida albicans, other Candida species, and Cryptococcus neoformans, ranged from $208 \mu \mathrm{g} / \mathrm{ml}$ to $1665 \mu \mathrm{g} / \mathrm{ml}$. Furthermore, SJA displayed fungicidal activity against varied fungi and obviously inhibited the hyphal growth of fungi. The mechanism study revealed that the antifungal activity of SJA might be associated with its effect on the cell morphology and ultrastructure.

\section{Introduction}

With increased patients with HIV infection, receiving different immunosuppressant treatments, antineoplastic chemotherapy, transplant recipients, or using catheters or other intravenous devices, invasive fungal infections are severe infections and constantly rising in the world [1-3]. Invasive candidiasis remains the most frequent mycosis and is often cited as the fourth most common cause of bloodstream infections with significant morbidity and mortality [4]. To date, common agents used in clinic to treat invasive fungal infections are azoles (e.g., fluconazole, itraconazole, voriconazole), echinocandins (e.g., caspofungin, anidulafungin, micafungin), and amphotericin B. However, progressive increase in exposing to azoles and echinocandins among Candida isolates commonly leads to resistant strains $[5,6]$. Some fungi are intrinsically resistant to certain antifungals, such as Candida krusei (to fluconazole) and Cryptococcus spp (to the echinocandins). Drug resistance in fungi worsened the already significant mortality associated with the invasive fungal infections [7].
To explore novel antifungal agents with new molecular mechanism is a valuable solution to this problem.

Traditional medicinal plants have been an important source to discover new agents or lead compounds in the history of drug research and development. A variety of herbal medicines, as Rosa chinensis Jacq., Indigofera suffruticosa Mill., Wrightia tinctoria R. Br., Mahonia aquifolium Nutt., Glycyrrhiza glabra L. and so on, were reported to exert antifungal activity [8-13]. In our screening study, we found that Maianthemum japonicum (A. Gray) LaFrankie, also called Smilacina japonica A. Gray, displayed potent antifungal and even fungicidal effect. Smilacina japonica A. Gray (SJA), locally called "PianTouQi", is a perennial herb which distributes widely in China. The tender aerial part is edible as a wild vegetable by local people. The rhizome and root have the ability of promoting blood circulation and alleviating pain. It has long been used as folk herbs for the treatment of internal lesion caused by overexertion, asynodia, headache, rheumatism, menstrual disturbance, mastitis, bruises, carbuncle, and furuncle [14]. 
Previous studies have reported that SJA had several pharmaceutical effects including antibacterial, antitumor, and antioxidant activities [14-16]. However, there are few studies on its mode of antifungal action. In this context, the antifungal activity of SJA and its possible mechanisms of action were reported.

\section{Materials and Methods}

2.1. Strains and Media. One clinical isolate of fluconazole (FCZ) resistant C. albicans (103), one international calibration strain (SC5314), one American type culture collection (ATCC)-typed Candida strain (C. parapsilosis ATCC22019), Cryptococcus neoformans 32609, C. krusei ATCC2340, C. glabrata ATCC1182, and C. tropicalis 2718 were utilized. SC5314 was kindly provided by William A. Fonzi (Department of Microbiology and Immunology, Georgetown University, Washington, DC). C. krusei ATCC2340 and C. glabrata ATCC1182 were kindly provided by professor Changzhong Wang (School of integrated traditional and western medicine, Anhui university of traditional Chinese medicine, Hefei, China). The other fungi strains were provided by the Changhai Hospital (Shanghai, China). Strains were cultured at $35^{\circ} \mathrm{C}$ under constant shaking $(200 \mathrm{rpm})$ in complete liquid medium (yeast extract peptone dextrose-YPD) consisting of $1 \%(\mathrm{w} / \mathrm{v})$ yeast extract, $2 \%(\mathrm{w} / \mathrm{v})$ peptone, and $2 \%(\mathrm{w} / \mathrm{v})$ dextrose.

2.2. Medicinal Material Extraction. The dried rhizome and root of SJA were bought from the fourth chain of Huaiya drug store belong to Meixian De-er-kang herbal medicine corporation in Shaanxi province with supply certificate. Approximate $5 \mathrm{~g}$ of dried and smashed SJA was extracted with an excess $100 \mathrm{ml}$ of $75 \%$ ethanol, then the extract was filtered. After removing the solvent by rotary evaporation under reduced pressure at $50^{\circ} \mathrm{C}$, the residue was dissolved with DMSO to approximately $0.333 \mathrm{~g} / \mathrm{ml}$ SJA. The final extract was dark brown liquid and stored at $-20^{\circ} \mathrm{C}$ for further use.

2.3. Antifungal Susceptibility Test. The antifungal susceptibility test was performed on all strains according to broth microdilution method as described previously [17]. C. parapsilosis ATCC22019 was used as a quality control strain and tested in each assay. FCZ was used as a positive drug control. The initial concentration of fungi suspended in RPMI 1640 medium was about $10^{3}$ cells $/ \mathrm{ml}$, and the initial concentration ranged from 0.125 to $64 \mu \mathrm{g} / \mathrm{ml}$ for FCZ and 6.5 to $3330 \mu \mathrm{g} / \mathrm{ml}$ for SJA. The 96 -well plates were incubated at $35^{\circ} \mathrm{C}$ for $24 \mathrm{~h}, 48$ $\mathrm{h}$ or $72 \mathrm{~h}$. The minimum inhibitory concentrations (MICs) were determined by optical density. Each strain was tested in triplicate.

2.4. Checkerboard Microdilution Assay. Assays were performed according to the above test 2.3. The combination concentrations ranged from 0.125 to $64 \mu \mathrm{g} / \mathrm{ml}$ for FCZ and 26 to $208 \mu \mathrm{g} / \mathrm{ml}$ for SJA. The fractional inhibitory concentration (FIC) index (FICI) was calculated by the following equation: FICI $=$ FIC A + FIC B, where FIC A is the MIC of the combination/the MIC of drug A alone, and FIC B is the MIC of the combination/the MIC of drug B alone. Synergy was defined as an FICI value of $\leq 0.5$, while antagonism was defined as an FICI value of $>4$, and the addition was defined as an FICI value of $0.5<\mathrm{FICI} \leq 1$. An FICI result between 1 and 4 was considered indifferent.

2.5. Cell Growth Test. Each fungus was prepared at the starting inoculum of $10^{6}$ cells $/ \mathrm{ml}$ in glass tubes. Different concentrations of SJA $(208 \mu \mathrm{g} / \mathrm{ml}, 416 \mu \mathrm{g} / \mathrm{ml}, 832 \mu \mathrm{g} / \mathrm{ml}$ and $3330 \mu \mathrm{g} / \mathrm{ml}$ ) and FCZ were added into tubes. After incubation with agitation at $35^{\circ} \mathrm{C}$ for $24 \mathrm{~h}$ or $48 \mathrm{~h}$, pictures were captured [18].

2.6. Time-Kill Curve Studies. Different fungi strains were prepared at the starting inoculum of $10^{5}$ cells $/ \mathrm{ml}$. The concentrations were $104 \mu \mathrm{g} / \mathrm{ml}, 208 \mu \mathrm{g} / \mathrm{ml}, 416 \mu \mathrm{g} / \mathrm{ml}$ or $832 \mu \mathrm{g} / \mathrm{ml}$ for SJA, and DMSO comprised $<1 \%$ of the total test volume. At predetermined time points $(0 \mathrm{~h}, 4 \mathrm{~h}, 8 \mathrm{~h}, 12 \mathrm{~h}, 16 \mathrm{~h}, 24 \mathrm{~h}$ and $48 \mathrm{~h}$ ) after incubation with agitation at $35^{\circ} \mathrm{C}$, a $100 \mu \mathrm{l}$ aliquot was removed from every solution and serially diluted $10-$ fold in sterile water. A $100 \mu \mathrm{l}$ aliquot from each dilution was spread on the sabouraud dextrose agar plate. Colony counts were determined after incubation at $35^{\circ} \mathrm{C}$ for $48 \mathrm{~h}$. Fungicidal activity was defined as a $\geq 3 \log _{10}$ reduction from the starting inoculums [19].

2.7. Hyphal Growth Test. C. albicans SC5314 cells were incubated at $37^{\circ} \mathrm{C}$ in RPMI 1640 for $3 \mathrm{~h}$ in the absence or in the presence of different concentrations of SJA $(416 \mu \mathrm{g} / \mathrm{ml}, 832$ $\mu \mathrm{g} / \mathrm{ml})$ or FCZ $(0.5 \mu \mathrm{g} / \mathrm{ml})$. All cells were viewed by light microscopy to assess hyphal formation [20].

2.8. Cell Membrane Permeability. Membrane permeabilization of C. albicans was detected according to the study [21]. Briefly, C. albicans SC5314 $\left(10^{7}\right.$ cells $\left./ \mathrm{ml}\right)$ was incubated with $5 \mathrm{mM}$ calcein acetoxy-methyl ester (Fanbo biochemicals, China) for $2 \mathrm{~h}$. Then the cells were washed three times and C. albicans $\left(10^{6}\right.$ cells $\left./ \mathrm{ml}\right)$ was transferred into tubes. After treating with or without SJA $(416 \mu \mathrm{g} / \mathrm{ml}, 832 \mu \mathrm{g} / \mathrm{ml})$ for 3 $\mathrm{h}$, the cells were washed three times and about 20,000 cells were acquired for flow cytometry analysis (Maflo Astrios flow cytometer).

2.9. Transmission Electron Microscopy (TEM). After treating with or without SJA $(416 \mu \mathrm{g} / \mathrm{ml}$ or $832 \mu \mathrm{g} / \mathrm{ml})$, C. albicans SC5314 was washed in PBS and fixed in $3 \mathrm{ml}$ fixative solution (sodium cacodylate buffer, $\mathrm{pH} 7.2$, containing 4\% polyoxymethylene) for $24 \mathrm{~h}$ at $4^{\circ} \mathrm{C}$. Then, the samples were washed with saline and postfixed with $1 \%$ phosphotungstic acid for 90 minutes. The fixed cells were dehydrated through a graded series of ethanol and embedded with EPON-812. Ultrathin sections were prepared and observed after double staining with uranium and lead under a transmission electron microscope (HITACHI H-800, Japan) [22].

2.10. Statistical Analysis. The two-tailed Student's t-test was used for analysis of two groups. Statistical significance was set at a $\mathrm{p}$-value in the figures as: $*, \mathrm{P}<0.05$. 
TABLE 1: Antifungal activity of SJA against different fungi $(\mu \mathrm{g} / \mathrm{ml})^{a}$.

\begin{tabular}{|c|c|c|c|c|}
\hline \multirow{3}{*}{ fungi } & \multicolumn{4}{|c|}{$\operatorname{MIC}(\mu \mathrm{g} / \mathrm{ml})$} \\
\hline & \multicolumn{2}{|c|}{$\mathrm{FCZ}^{b}$} & \multicolumn{2}{|c|}{ SJA } \\
\hline & $24 \mathrm{~h}$ & $48 \mathrm{~h}$ & $24 \mathrm{~h}$ & $48 \mathrm{~h}$ \\
\hline FCZ-resistant C. albicans 103 & $>64$ & $>64$ & $416-832$ & $416-832$ \\
\hline C. albicans SC5314 & $0.5-1$ & 1 & $416-832$ & $416-832$ \\
\hline Cryptococcus neoformans & $1-2$ & 2 & 208 & $208-416$ \\
\hline C. krusei & $>64$ & $>64$ & 1665 & $1665-3330$ \\
\hline C. parapsilosis & 2 & 2 & 416 & $416-832$ \\
\hline C. glabrata & $>64$ & $>64$ & 416 & $208-416$ \\
\hline C. tropicalis & $>64$ & $>64$ & $208-416$ & $416-832$ \\
\hline
\end{tabular}

${ }^{a}$ SJA, Smilacina japonica A. Gray; ${ }^{b}$ FCZ, fluconazole.

TABLE 2: Activity of SJA alone and in combination with FCZ against different fungi $(\mu \mathrm{g} / \mathrm{ml})^{a}$.

\begin{tabular}{lcccccc}
\hline \multirow{2}{*}{ fungi } & \multicolumn{2}{c}{ Alone } & \multicolumn{2}{c}{ Combination } & \multirow{2}{*}{ FIC index for combination } & \multirow{2}{*}{ Mode of interaction } \\
& FCZ $^{b}$ & SJA & FCZ $^{b}$ & SJA & addition \\
FCZ-resistant C. albicans 103 & $>64$ & 416 & 64 & 208 & 1.000 & indifference \\
C. albicans SC5314 & 1 & 416 & 1 & 26 & 0.125 & synergism \\
Cryptococcus neoformans & 2 & 208 & 0.5 & 26 & 0.188 & synergism \\
C. krusei & $>64$ & 1665 & 8 & 208 & 0.563 & addition \\
C. parapsilosis & 2 & 416 & 1 & 26 & 1.500 & indifference \\
C. glabrata & $>64$ & 416 & $>64$ & 208 & 1.000 & addition \\
C. tropicalis & $>64$ & 416 & 64 & 208 & & \\
\hline
\end{tabular}

${ }^{a}$ SJA, Smilacina japonica A. Gray; ${ }^{b} \mathrm{FCZ}$, fluconazole.

\section{Results}

3.1. Fungi Growth Was Inhibited by SJA. The results of the antifungal susceptibility test were summarized in Table 1. SJA displayed a broad-spectrum antifungal activity. The MICs of SJA against different fungi, including FCZ-sensitive and resistant C. albicans, other Candida species and Cryptococcus neoformans, ranged from $208 \mu \mathrm{g} / \mathrm{ml}$ to $1665 \mu \mathrm{g} / \mathrm{ml}$ at 24 $\mathrm{h}$ or $48 \mathrm{~h}$. To further visualize the activity of SJA against these fungi, we evaluated the growth of fungi after incubation with different concentrations of SJA for $24 \mathrm{~h}$ and $48 \mathrm{~h}$. SJA at $416 \mu \mathrm{g} / \mathrm{ml}, 832 \mu \mathrm{g} / \mathrm{ml}$ and $3330 \mu \mathrm{g} / \mathrm{ml}$ displayed potent growth inhibition activity against all the tested fungi except $C$. krusei (Figure 1). In addition, SJA at $208 \mu \mathrm{g} / \mathrm{ml}$ also exhibited significant growth inhibition against part fungi (Cryptococcus neoformans, C. glabrata, C. parapsilosis and C. tropicalis).

To evaluate the interaction of SJA with antifungal drug FCZ, checkerboard microdilution assays were tested. As shown in Table 2, synergisms were observed for Cryptococcus neoformans and C. krusei, while additions were found for FCZ-resistant C. albicans 103, C. parapsilosis and C. tropicalis. Indifferences were observed for C. albicans SC5314 and C. glabrata.

To evaluate whether SJA had fungicidal activity against fungi, time-kill curve studies were performed. As shown in Figure 2, SJA displayed potent fungicidal effect against different fungi except C. krusei, which was consistent with the results of cell growth test. SJA at $208 \mu \mathrm{g} / \mathrm{ml}$ displayed fungicidal effect against FCZ-resistant C. albicans 103 and led to a decrease of $1.68-\log _{10}$ Colony-forming units (CFU)
$/ \mathrm{ml}$ at $4 \mathrm{~h}$ compared with the initial inoculum concentration (Figure 2(a)). Moreover, SJA at $208 \mu \mathrm{g} / \mathrm{ml}, 416$ $\mu \mathrm{g} / \mathrm{ml}$ and $832 \mu \mathrm{g} / \mathrm{ml}$ resulted in a complete cell-killing at 8 h. For C. albicans SC5314 (Figure 2(b)). SJA also displayed fungicidal effect. SJA at $208 \mu \mathrm{g} / \mathrm{ml}$ yielded a $6.1-$ $\log _{10} \mathrm{CFU} / \mathrm{ml}$ reduction compared with the control at 24 h. More specifically, SJA at $208 \mu \mathrm{g} / \mathrm{ml}, 416 \mu \mathrm{g} / \mathrm{ml}$ and 832 $\mu \mathrm{g} / \mathrm{ml}$ exhibited a complete cell-killing at $48 \mathrm{~h}$. For other fungi (Cryptococcus neoformans, C. glabrata, C. parapsilosis and C. tropicalis), both $416 \mu \mathrm{g} / \mathrm{ml}$ and $832 \mu \mathrm{g} / \mathrm{ml} \mathrm{SJA} \mathrm{resulted}$ in a complete cell-killing at $24 \mathrm{~h}$, and the densities of fungi cells were all reduced to zero. These results confirmed that SJA had excellent fungicidal activity against varied fungi.

3.2. Hyphal Growth of Fungi Was Inhibited by SJA. Fungi like $C$. albicans can grow in three types of morphological forms including yeast, pseudohyphae, and hyphae. During the early stage of infection, yeast fungi become hyphae form to penetrate human epithelial and endothelial cells and cause the damage to them $[23,24]$. In addition, to resist standard antifungal treatments, fungi can form biofilms which contain hyphae [25]. Therefore, the activity of SJA on the growth of fungal hyphae was determined. In the blank control group (Figure 3), C. albicans showed elongated hyphae forms after $3 \mathrm{~h}$ incubation. After treating with SJA at $416 \mu \mathrm{g} / \mathrm{ml}$ or $832 \mu \mathrm{g} / \mathrm{ml}$, most of the C. albicans did not germinate and appeared as yeast form. More interestingly, C. albicans progressively aggregated and became clumps after treating with $832 \mu \mathrm{g} / \mathrm{ml}$ of SJA for $2 \mathrm{~h}$ and $3 \mathrm{~h}$. 
$24 \mathrm{~h}$

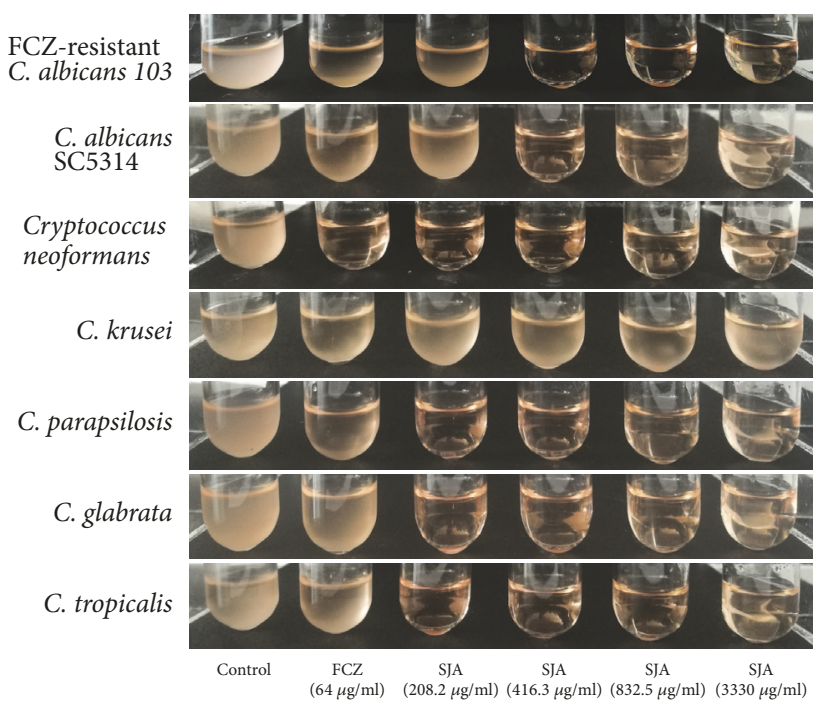

$48 \mathrm{~h}$

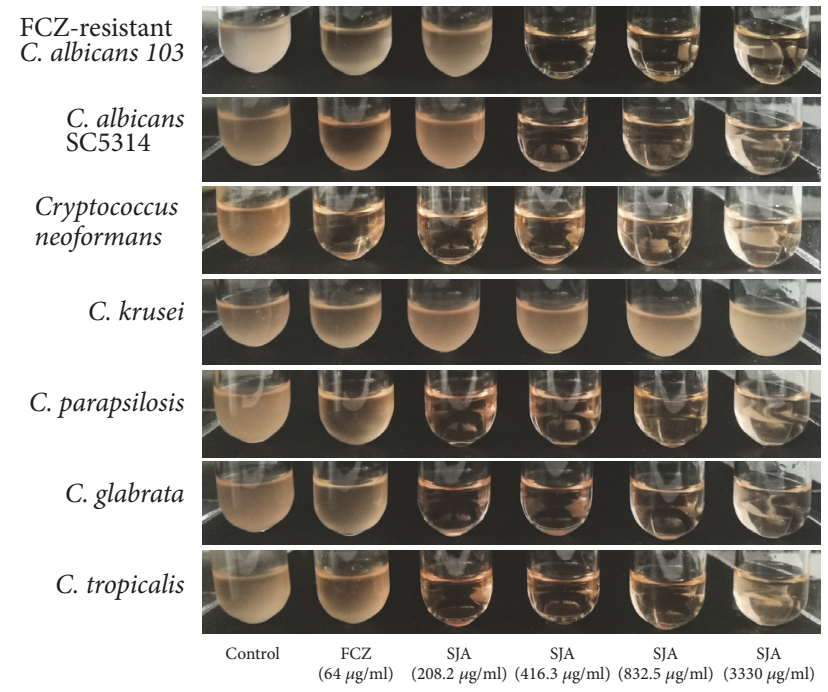

FIGURE 1: SJA inhibits the growth of part fungi. Different fungi strains with an initial inoculum of about $10^{6}$ cells/ml were exposed to 64 $\mu \mathrm{g} / \mathrm{ml} \mathrm{FCZ} \mathrm{or} \mathrm{different} \mathrm{concentrations} \mathrm{of} \mathrm{SJA}(208 \mu \mathrm{g} / \mathrm{ml}, 416 \mu \mathrm{g} / \mathrm{ml}, 832 \mu \mathrm{g} / \mathrm{ml}$ and $3330 \mu \mathrm{g} / \mathrm{ml})$. Pictures were captured after $24 \mathrm{~h}$ and $48 \mathrm{~h}$ of incubation.

3.3. The Cell Size and the Membrane Permeability of Fungi Were Increased by SJA. Flow cytometry analysis (side scatter [SSC]-forward light scatter [FSC]) revealed that C. albicans SC5314 treated with SJA ( $416 \mu \mathrm{g} / \mathrm{ml}$ or $832 \mu \mathrm{g} / \mathrm{ml})$ exhibited a significant increase in cell size, as evidenced by the increase in forward light scattering (Figure 4).

Calcein AM is a non-fluorescent, hydrophobic compound that easily permeates intact, live cells. Once into the cytoplasm of cells, calcein AM is hydrolyzed by cytoplasmic esterases, producing membrane-impermeable, hydrophilic and strongly fluorescent calcein which can be well-retained in intact cell cytoplasm. After incubation with calcein AM, the cellular fluorescence of calcein was detected by flow cytometry to evaluate the effect of SJA on the cell membrane permeabilization. Result displayed that cellular fluorescence of calcein was markedly decreased by treatment of Candida cells with different concentrations of SJA (416 $\mu \mathrm{g} / \mathrm{ml}$ or $832 \mu \mathrm{g} / \mathrm{ml}$ ) compared with the blank control cells (Figure 5). The results indicated that SJA interrupted the Candida cell membrane and increased the cell membrane permeability.

3.4. The Ultrastructure of Fungi Was Damaged by SJA. In order to explore the antifungal mechanism of SJA, the ultrastructure of C. albicans was monitored by TEM. As shown in Figure 6, the control Candida cells have a uniform central density and an intact cell wall. After treatment of SJA at 416 $\mu \mathrm{g} / \mathrm{ml}$ or $832 \mu \mathrm{g} / \mathrm{ml}$, the outer layer of the cell wall became thinner, and the middle layer became thicker. Some abnormal shapes of the vacuoles were also observed. In addition, reduced cytoplasmic density and damaged membranes could be observed. The TEM results indicated that SJA caused obvious damage on the ultrastructure of C. albicans including cell wall and membrane structures.

\section{Discussion}

Fungal diseases cause considerable morbidity and mortality globally and elevate health care costs [26]. The paucity of effective antifungal agents and emergency of drug resistance prompted researchers to develop novel antifungal agents [7]. Natural products are a valuable source for drug discovery, whether in their nascent form as original templates for structure-optimizing for more effective and safe derivatives. About $80 \%$ of marketed antibiotics used clinically are derived from natural products $[27,28]$. Current antifungal drugs like echinocandins and amphotericin $\mathrm{B}$ are also developed from natural resources. A variety of natural products, as peptides, saponins, flavonoids, alkaloids, essential oils, and so on, have been found to possess antifungal activity [29-33]. As a traditional Chinese medicine, SJA has various therapeutic effects. However, to the best of our knowledge, there was no investigation on the action of SJA against fungi.

In this study, we demonstrated that SJA had antifungal activity against different fungi including Candida species and Cryptococcus neoformans (with MICs ranging from 208 $\mu \mathrm{g} / \mathrm{ml}$ to $1665 \mu \mathrm{g} / \mathrm{ml}$ ). In light of the definitions of fungicidal effect through time-kill curve tests, a fungicidal effect was defined as a reduction in $\geqq 3 \log _{10} \mathrm{CFU} / \mathrm{ml}$ compared to initial inoculum [34]. Therefore, SJA was considered fungicidal. Previously, the antifungal effect of steroidal saponins extracted from the genus Smilacina called Smilacina atropurpurea (Franch.) Wang et Tang (Convallariaceae) was studied by Ying Zhang et al. [35]. Among eight saponins, they found that astropuroside $\mathrm{B}$ and $\mathrm{F}$ exhibited fungicidal activity against C. albicans, C. glabrata, Cryptococcus neoformans and Aspergillus fumigates with MFCs $\leq 20 \mu \mathrm{g} / \mathrm{ml}$ except C. krusei, while dioscin was selectively active against $C$. albicans and C. glabrata (MFC $\leq 5.0 \mu \mathrm{g} / \mathrm{ml}$ ) [35]. Compared to Smilacina atropurpurea, the extract of SJA exhibited similar fungicidal 


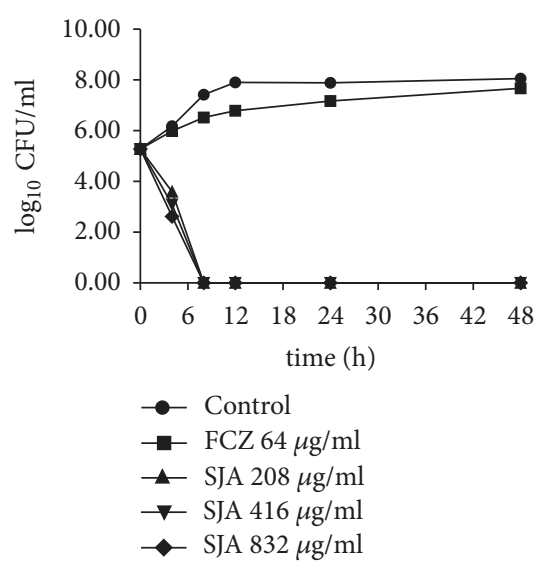

(a)

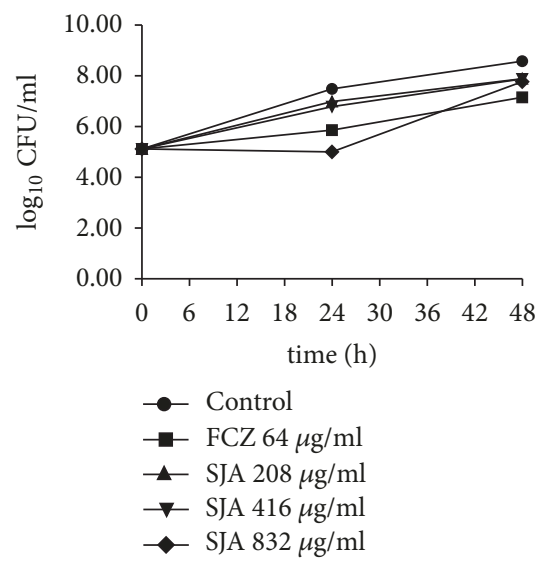

(d)

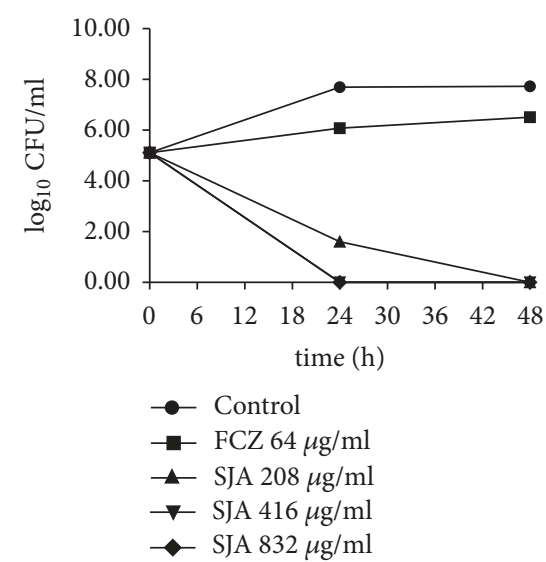

(b)

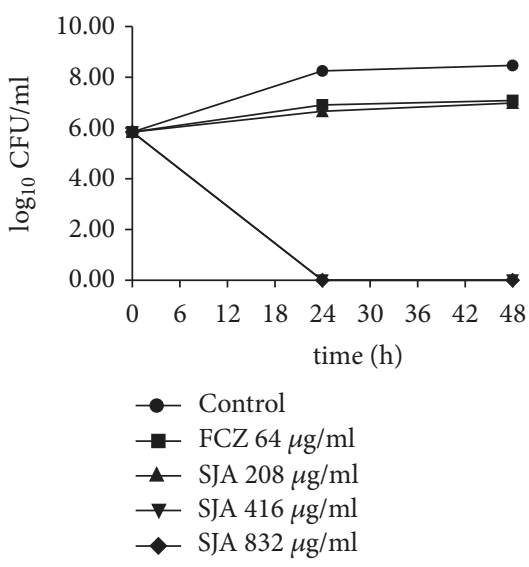

(e)

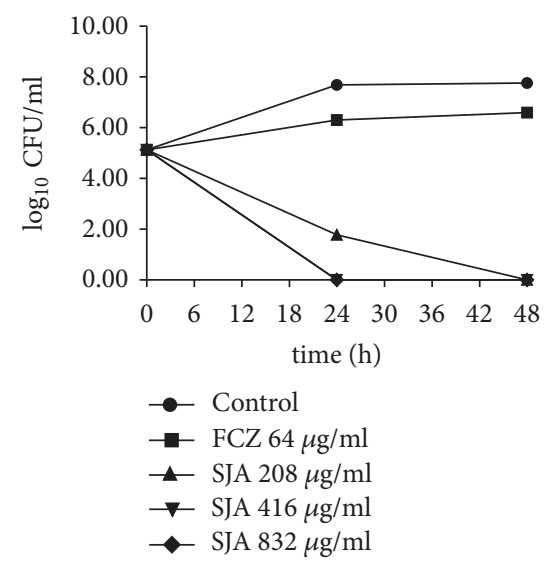

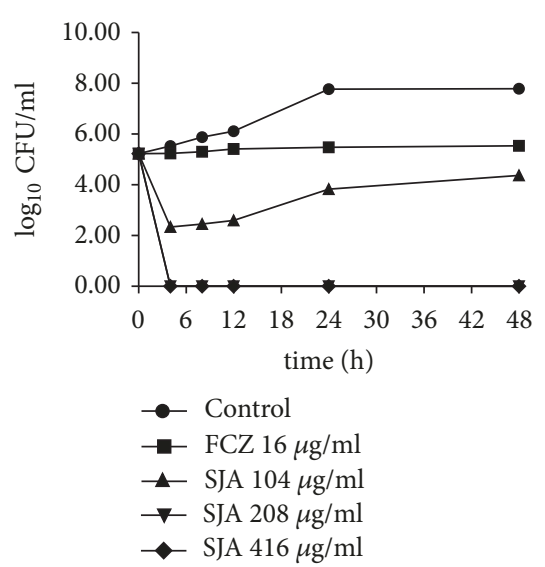

(c)

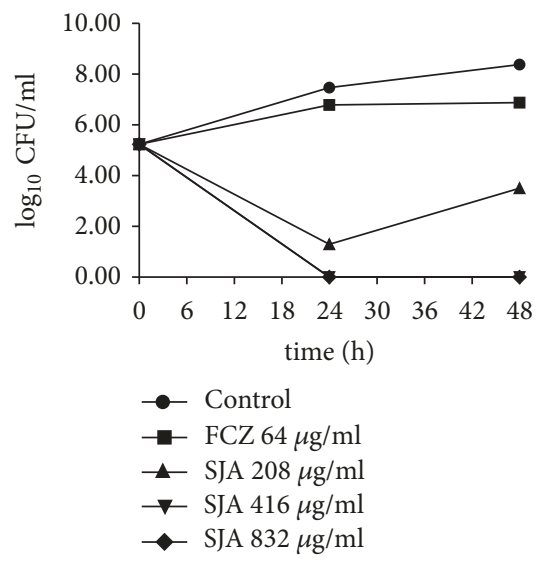

(f)

(g)

FIGURE 2: Time kill curves of various fungi treated with different concentrations of SJA and FCZ. FCZ-resistant C. albicans 103 (a), C. albicans SC5314 (b), Cryptococcus neoformans (c), C. krusei (d), C. parapsilosis (e), C. glabrata (f) and C. tropicalis (g) were treated with different concentrations of SJA $(104 \mu \mathrm{g} / \mathrm{ml}, 208 \mu \mathrm{g} / \mathrm{ml}, 416 \mu \mathrm{g} / \mathrm{ml}$ and $832 \mu \mathrm{g} / \mathrm{ml})$ for $48 \mathrm{~h}$. Aliquots were obtained at the indicated time points and serially dilutions were spread on agar plates. Colony counts were determined after $48 \mathrm{~h}$ incubation.

effect, but it had a broader antifungal spectrum. According to previous reports on the constituents of the two plants, there are differences in the chemical structures of saponins isolated from Smilacina atropurpurea and SJA [14,36-38]. In addition, the report by Ying Zhang et al. also suggested that not all saponins had antifungal activity [35]. Therefore, our group will perform more studies to explore the exact antifungal ingredients of SJA in collaboration with the other laboratory.

Hyphae play an important role in the fungal infection and biofilm formation. SJA was able to suppress the hyphal 


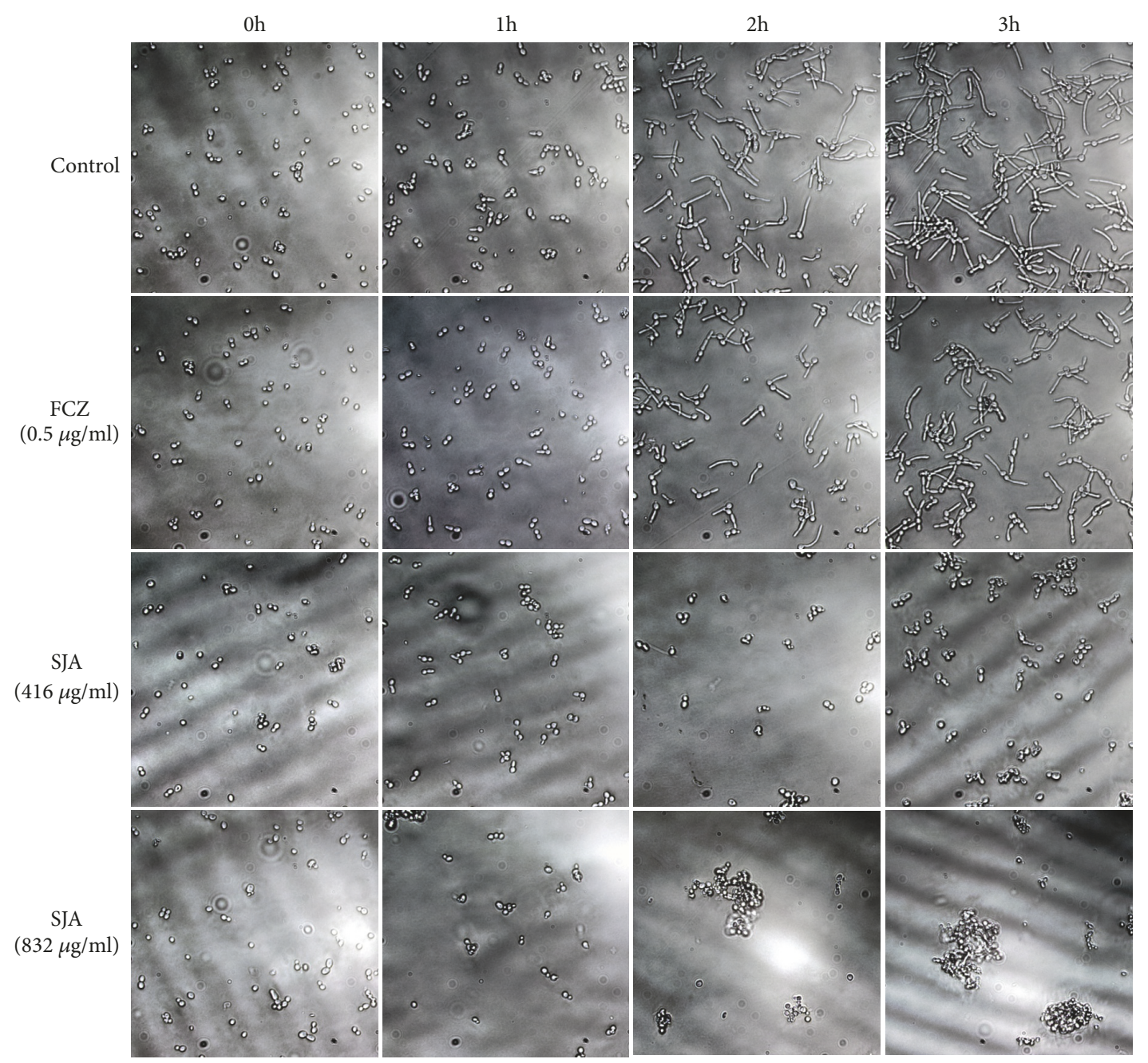

FIGURE 3: SJA inhibits the hyphal growth of fungi. The C. albicans SC5314 cells were incubated in RPMI 1640 liquid medium at $37^{\circ} \mathrm{C}$ for 3 $\mathrm{h}$ in the absence or presence of different concentrations of SJA $(416 \mu \mathrm{g} / \mathrm{ml}$ or $832 \mu \mathrm{g} / \mathrm{ml})$ or FCZ $(0.5 \mu \mathrm{g} / \mathrm{ml})$. The hyphal development was viewed by light microscopy and photographed after $0 \mathrm{~h}, 1 \mathrm{~h}, 2 \mathrm{~h}$ and $3 \mathrm{~h}$ of incubation.
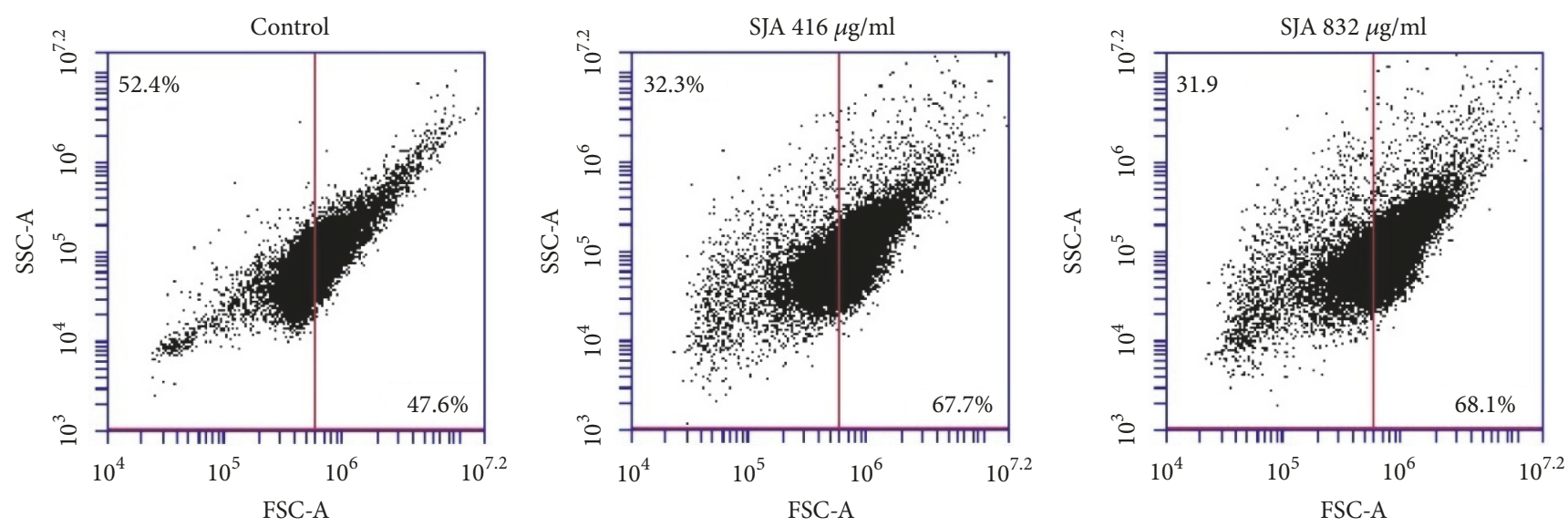

FIGURE 4: Change of cell size (forward scatter-side scatter) in the presence of SJA. C. albicans SC5314 were treated with or without SJA (416 $\mu \mathrm{g} / \mathrm{ml}$ to $832 \mu \mathrm{g} / \mathrm{ml}$ ) for $3 \mathrm{~h}$. Then the cells were analyzed by flow cytometry. 


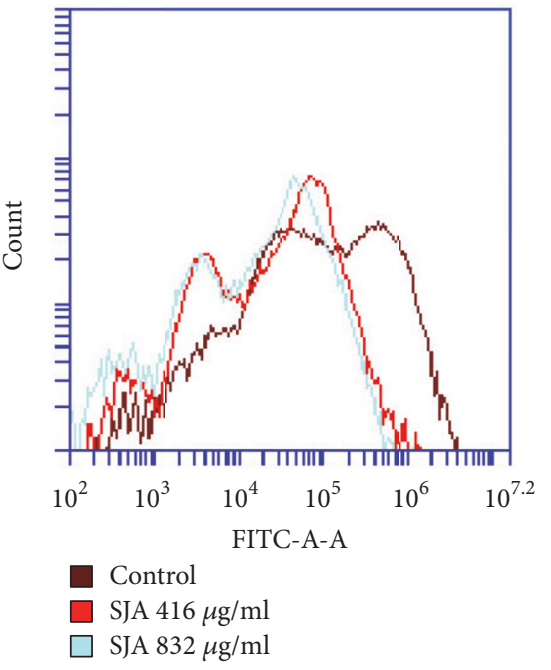

(a)

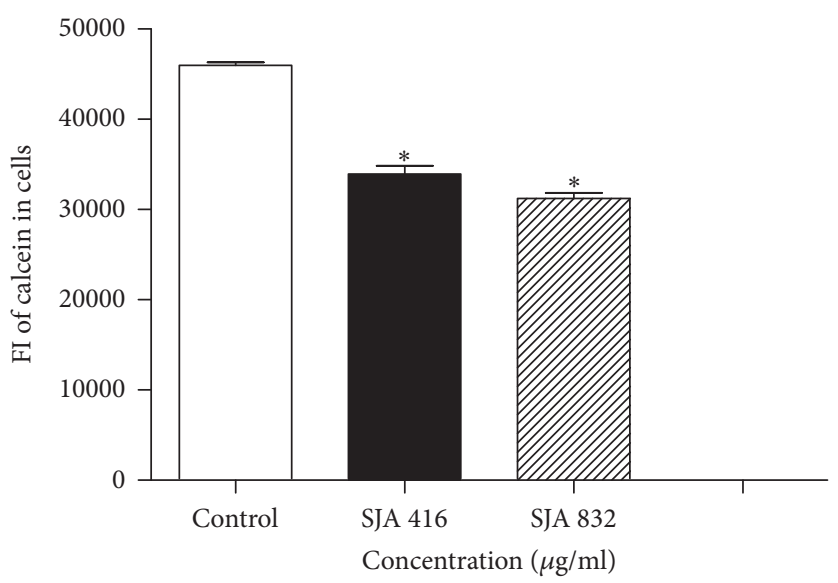

(b)

Figure 5: The effect of SJA on cell membrane permeability. Candida cells $\left(10^{7}\right.$ cells $\left./ \mathrm{ml}\right)$ were cultured in the presence of $5 \mu \mathrm{M}$ calcein acetoxymethylester for $2 \mathrm{~h}$. After washing three times, the cells were cultured in the presence or absence of SJA (416 $\mu \mathrm{g} / \mathrm{ml}$ to $832 \mu \mathrm{g} / \mathrm{ml})$ for $3 \mathrm{~h}$. Cellular fluorescence intensities of calcein were analyzed by flow Cytometry. Data are means \pm SD of triplicates of one representative experiment of three. $*, \mathrm{P}<0.05$, Student's t-test.

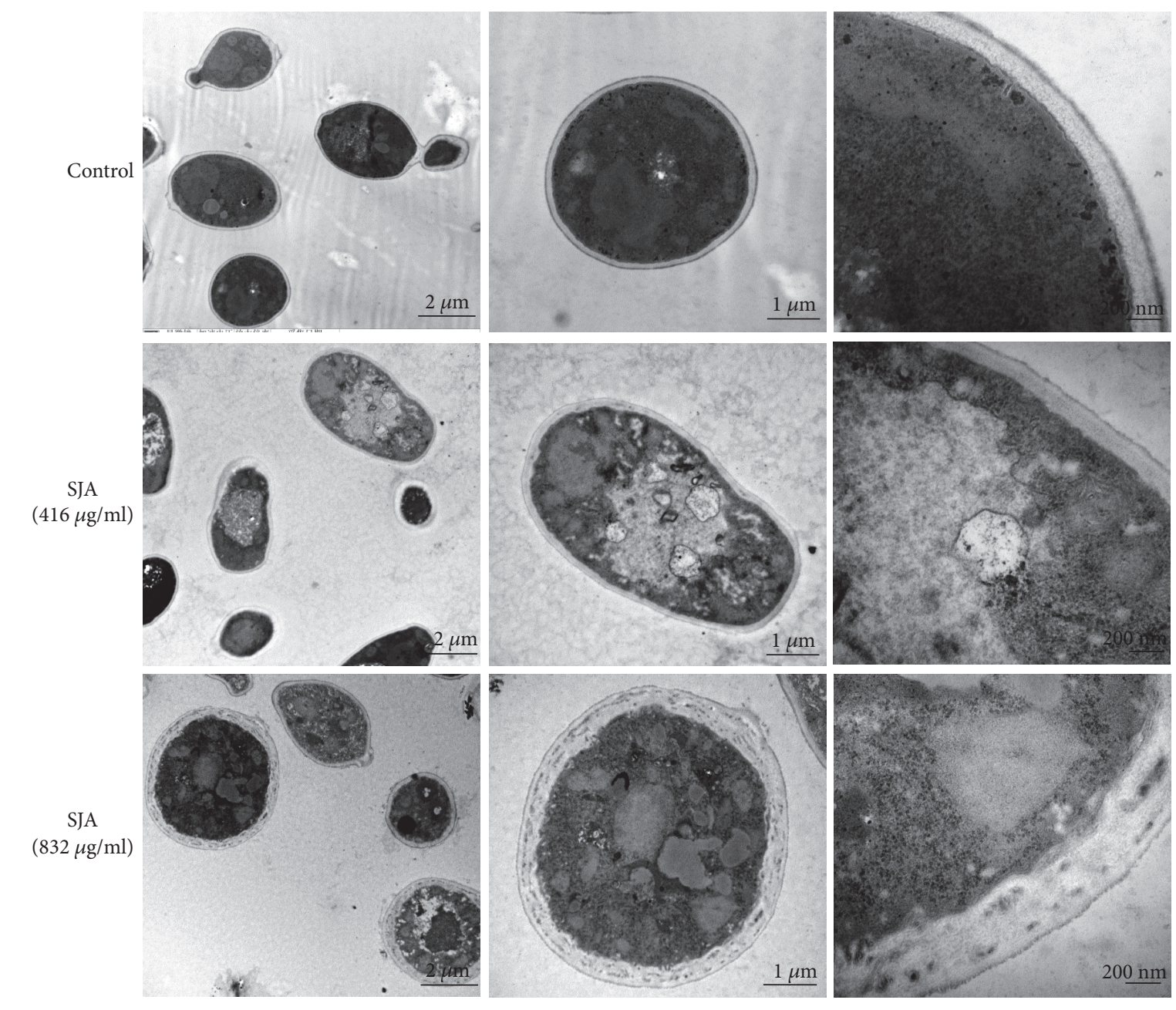

FIGURE 6: TEM results of Candida cells treated with or without SJA $(416 \mu \mathrm{g} / \mathrm{ml}$ or $832 \mu \mathrm{g} / \mathrm{ml})$. 
growth of C. albicans. Besides, through the analysis of cellular fluorescent calcein by flow cytometry, we demonstrated that SJA could increase the membrane permeability. The yeastto-hypha inhibition and the membrane-perturbation effect of SJA are akin to the other saponins like saponin extract from rhizomes of Dioscorea panthaica Prain et Burk and tea saponin [30,39].

TEM results showed that SJA obviously damaged the ultrastructure of fungi including the membrane structures and cell wall. Lesions were observed on membrane structures, including the cytoplasmic membrane and organelle membranes such as nucleus and mitochondria. The membrane damage of SJA may contribute to the increased membrane permeability and cell size of fungi. SJA also exhibited a harmful effect on the cell wall, such as the outer layer of the cell wall became thinner, and the middle layer became thicker. Cell wall plays a crucial role in the fungal commensalism and infection [40]. It offers mechanical strength and acts as a barrier, thus protecting the fungus from the hostile environment. Besides, the cell wall glucan plays an important role in the yeast-to-hypha transition [41]. This suggests the hyphal growth inhibition of SJA may be related to its damage on the ultrastructure like cell wall. The harmful effects on the membrane and cell wall of SJA are similar to the Solanum chrysotrichum saponin SC-2 and saponin extract from rhizomes of Dioscorea panthaica Prain et Burk [30, 42].

\section{Conclusion}

The present study connoted that SJA has strong fungicidal activity against different fungi such as Candida species and Cryptococcus neoformans. SJA could also inhibit the yeasthypha transition and increase membrane permeability and cell size of C. albicans. The antifungal effects might be through membrane and cell wall damage. As a traditional Chinese medicine, SJA represents a promising herbal medicine for the discovery of novel antifungal compounds. The exact antifungal ingredients and action mechanisms are under investigation in our laboratories.

\section{Data Availability}

The data used to support the findings of this study are available from the corresponding author upon request.

\section{Conflicts of Interest}

The authors declare that they have no conflicts of interest.

\section{Authors' Contributions}

Wei Liu and Shengzheng Wang are responsible for drafting the paper. Wei Liu participated in the study design, collection and analysis of data, review and drafting the paper. Baozheng Sun, Manman Yang, Ziyue Zhang, Xiuxiu Zhang and Yansong Pang participated in part data collection, data analysis, and revision of the paper. Shengzheng Wang guided all stages of the study and participated in both review and drafting of the paper.

\section{Acknowledgments}

This work was supported by National Natural Science Foundation of China (Grants 81701981 to Wei Liu and 21602252 to Sheng-Zheng Wang), Natural Science Foundation of Shaanxi (Grant 2018JQ8006 to Wei Liu) and the Hong Kong Scholars Program (XJ201713 to Sheng-Zheng Wang), and Undergraduate Training Programs for Innovation and Entrepreneurship of Shaanxi (Grant 201810077 to Baozheng Sun).

\section{References}

[1] G. Suleyman and G. J. Alangaden, "Nosocomial fungal infections," Infectious Disease Clinics of North America, vol. 30, no. 4, pp. 1023-1052, 2016.

[2] G. D. Brown, D. W. Denning, and S. M. Levitz, "Tackling human fungal infections," Science, vol. 336, no. 6082, article no. 647, 2012.

[3] D. Bitar, O. Lortholary, Y. Le Strat et al., "Population-based analysis of invasive fungal infections, France, 2001-2010," Emerging Infectious Diseases, vol. 20, no. 7, pp. 1163-1169, 2014.

[4] S. Strollo, M. S. Lionakis, J. Adjemian, C. A. Steiner, and D. R. Prevots, "Epidemiology of hospitalizations associated with invasive candidiasis, United States, 2002-20121," Emerging Infectious Diseases, vol. 23, no. 1, pp. 7-13, 2016.

[5] M. Baixench, N. Aoun, M. Desnos-Ollivier et al., "Acquired resistance to echinocandins in Candida albicans: case report and review," Journal of Antimicrobial Chemotherapy, vol. 59, no. 6, pp. 1076-1083, 2007.

[6] C. Biswas, S. Chen, C. Halliday et al., "Identification of genetic markers of resistance to echinocandins, azoles and 5fluorocytosine in Candida glabrata by next-generation sequencing: a feasibility study," Clinical Microbiology and Infection, vol. 23, no. 9, pp. 676.e7-676.e10, 2017.

[7] D. W. Denning and M. J. Bromley, "Infectious disease. how to bolster the antifungal pipeline," Science, vol. 347, no. 6229, pp. 1414-1416, 2015.

[8] L. Zhang, H. Lin, W. Liu et al., "Antifungal Activity of the ethanol extract from flos rosae chinensis with activity against fluconazole-resistant clinical Candida," Evidence-Based Complementary and Alternative Medicine, vol. 2017, Article ID 4780746, 10 pages, 2017.

[9] S. P. Leite, J. R. Vieira, P. L. de Medeiros et al., "Antimicrobial Activity of Indigofera suffruticosa," Evidence-Based Complementary and Alternative Medicine, vol. 3, no. 2, Article ID 839056, pp. 261-265, 2006.

[10] K. Ponnusamy, C. Petchiammal, R. Mohankumar, and W. Hopper, "In vitro antifungal activity of indirubin isolated from a South Indian ethnomedicinal plant Wrightia tinctoria R. Br," Journal of Ethnopharmacology, vol. 132, no. 1, pp. 349-354, 2010.

[11] A. Volleková, D. Kost'alova, V. Kettmann, and J. Tóth, "Antifungal activity of Mahonia aquifolium extract and its major protoberberine alkaloids," Phytotherapy Research, vol. 17, no. 7, pp. 834-837, 2003.

[12] A. Fatima, V. K. Gupta, S. Luqman et al., “Antifungal activity of Glycyrrhiza glabra extracts and its active constituent glabridin ," Phytotherapy Research, vol. 23, no. 8, pp. 1190-1193, 2009. 
[13] N. I. Mongalo, P. M. Dikhoba, S. O. Soyingbe, and T. J. Makhafola, "Antifungal, anti-oxidant activity and cytotoxicity of South African medicinal plants against mycotoxigenic fungi," Heliyon, vol. 4, no. 11, Article ID e00973, 2018.

[14] X. Liu, H. Zhang, X. Niu, W. Xin, and L. Qi, "Steroidal saponins from Smilacina japonica," Fitoterapia, vol. 83, no. 4, pp. 812-816, 2012.

[15] S. Zhao, Z. Han, Y. Li, and L. Yang, "Study on the scavenging hydroxyl radical of the extracts from Smilacina japonica," Journal of South China Agricultural University, vol. 31, no. 2, pp. 59-62, 2010.

[16] Q. Ren, "Experimental Studies of antibacterial effect of 80 species of herbs from the qin mountains," Territory \& Natural Resources Study, vol. 7853, no. 1, pp. 86-88, 2013.

[17] H. Quan, Y.-Y. Cao, Z. Xu et al., "Potent in vitro synergism of fluconazole and berberine chloride against clinical isolates of Candida albicans resistant to fluconazole," Antimicrobial Agents and Chemotherapy, vol. 50, no. 3, pp. 1096-1099, 2006.

[18] W. Liu, L. P. Li, J. D. Zhang et al., "Synergistic antifungal effect of glabridin and fluconazole," PLoS ONE, vol. 9, no. 7, Article ID e103442, 10 pages, 2014.

[19] E. E. Roling, M. E. Klepser, A. Wasson, R. E. Lewis, E. J. Ernst, and M. A. Pfaller, "Antifungal activities of fluconazole, caspofungin (MK0991), and anidulafungin (LY 303366) alone and in combination against Candida spp. and Crytococcus neoformans via time-kill methods," Diagnostic Microbiology and Infectious Disease, vol. 43, no. 1, pp. 13-17, 2002.

[20] S. Wang, Y. Wang, W. Liu et al., "Novel carboline derivatives as potent antifungal lead compounds: design, synthesis, and biological evaluation," ACS Medicinal Chemistry Letters, vol. 5, no. 5, pp. 506-511, 2014.

[21] T. Tanida, T. Okamoto, E. Ueta, T. Yamamoto, and T. Osaki, "Antimicrobial peptides enhance the candidacidal activity of antifungal drugs by promoting the efflux of ATP from Candida cells," Journal of Antimicrobial Chemotherapy, vol. 57, no. 1, pp. 94-103, 2006.

[22] W. Liu, Z. Zou, X. Huang et al., "Bstl is required for Candida albicans infecting host via facilitating cell wall anchorage of Glycosylphosphatidyl inositol anchored proteins," Scientific Reports, vol. 6, no. 28, Article ID 34854, 2016.

[23] I. D. Jacobsen, D. Wilson, B. Wächtler, S. Brunke, J. R. Naglik, and B. Hube, "Candida albicans dimorphism as a therapeutic target," Expert Review of Anti-infective Therapy, vol. 10, no. 1, pp. 85-93, 2012.

[24] F. Dalle, B. Wächtler, C. L'Ollivier et al., "Cellular interactions of Candida albicans with human oral epithelial cells and enterocytes," Cellular Microbiology, vol. 12, no. 2, pp. 248-271, 2010.

[25] M. Cavalheiro and M. C. Teixeira, "Candida biofilms: threats, challenges, and promising strategies," Frontiers in Medicine, vol. 5, p. 28, 2018.

[26] S. Vallabhaneni, R. K. Mody, T. Walker, and T. Chiller, "The global burden of fungal diseases," Infectious Disease Clinics of North America, vol. 30, no. 1, pp. 1-11, 2016.

[27] M. G. Moloney, "Natural products as a source for novel antibiotics," Trends in Pharmacological Sciences, vol. 37, no. 8, pp. 689-701, 2016.

[28] T. Roemer, D. Xu, S. B. Singh et al., "Confronting the challenges of natural product-based antifungal discovery," Chemistry \& Biology, vol. 18, no. 2, pp. 148-164, 2011.
[29] S. S. Seyedjavadi, S. Khani, H. Zare-Zardini et al., "Isolation, functional characterization, and biological properties of MCh-AMP1, a novel antifungal peptide from Matricaria chamomilla L," Chemical Biology \& Drug Design, vol. 93, no. 5, pp. 949-959, 2019.

[30] L. Yang, X. Liu, X. Zhuang, X. Feng, L. Zhong, and T. $\mathrm{Ma}$, "Antifungal Effects of Saponin Extract from Rhizomes of Dioscorea panthaica Prain et Burk against Candida albicans," Evidence-Based Complementary and Alternative Medicine, vol. 2018, Article ID 6095307, 13 pages, 2018.

[31] T. M. Souza-Moreira, J. A. Severi, E. R. Rodrigues et al., "Flavonoids from Plinia cauliflora (Mart.) Kausel (Myrtaceae) with antifungal activity," Natural Product Research (Formerly Natural Product Letters), vol. 33, no. 17, pp. 2579-2582, 2018.

[32] J. Noguti, M. Rajinia, B. R. Zancope et al., "Antifungal activity of alkaloids against candida albicans," Journal of the California Dental Association, vol. 44, no. 8, pp. 493-498, 2016.

[33] H. Mafakheri and S. M. Mirghazanfari, "Antifungal activity of the essential oils of some medicinal plants against human and plant fungal pathogens," Cellular and Molecular Biology, vol. 64, no. 15, pp. 13-19, 2019.

[34] S. Tobudic, C. Forstner, H. Schranz, W. Poeppl, A. Vychytil, and $\mathrm{H}$. Burgmann, "Comparative in vitro fungicidal activity of echinocandins against Candida albicans in peritoneal dialysis fluids," Mycoses, vol. 56, no. 6, pp. 623-630, 2013.

[35] Y. Zhang, H. Li, Y. Zhang et al., "Atropurosides A-G, new steroidal saponins from smilacina atropurpurea," Steroids, vol. 71, no. 8, pp. 712-719, 2006.

[36] Y. Cui, X. Yang, D. Zhang et al., "Steroidal constituents from roots and rhizomes of smilacina japonica," Molecules, vol. 23, no. 4, p. 798, 2018.

[37] S. Zhao, L. Yang, Z. Han, and M. Han, "[Furosteroidal saponin from Smilacina japonica]," Zhongguo Zhong Yao Za Zhi, vol. 36, no. 24, pp. 3453-3456, 2011.

[38] Z. Shu-jie, H. Bo, H. Zhong-ming, and Y. Li-min, "Chemical constituents and their anti-tumor activities of Smilacina japonica," Chinese Traditional Patent Medicine, vol. 38, pp. 332-335, 2016.

[39] X. Jiang, K. Feng, and X. Yang, "In vitro antifungal activity and mechanism of action of tea polyphenols and tea saponin against rhizopus stolonifer," Journal of Molecular Microbiology and Biotechnology, vol. 25, no. 4, pp. 269-276, 2015.

[40] N. A. Gow and B. Hube, "Importance of the Candida albicans cell wall during commensalism and infection," Current Opinion in Microbiology, vol. 15, no. 4, pp. 406-412, 2012.

[41] D. W. Lowman, R. R. Greene, D. W. Bearden et al., "Novel structural features in Candida albicans hyphal glucan provide a basis for differential innate immune recognition of hyphae versus yeast," The Journal of Biological Chemistry, vol. 289, no. 6, pp. 3432-3443, 2014.

[42] A. Herrera-Arellano, M. Martínez-Rivera, M. Hernández-Cruz et al., "Mycological and electron microscopic study of solanum chrysotrichum saponin sc-2 antifungal activity on Candida species of medical significance," Planta Medica, vol. 73, no. 15, pp. 1568-1573, 2007. 


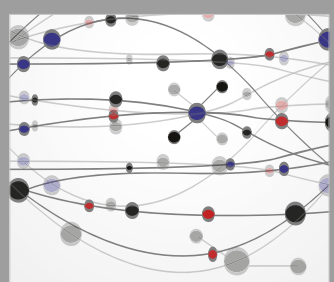

The Scientific World Journal
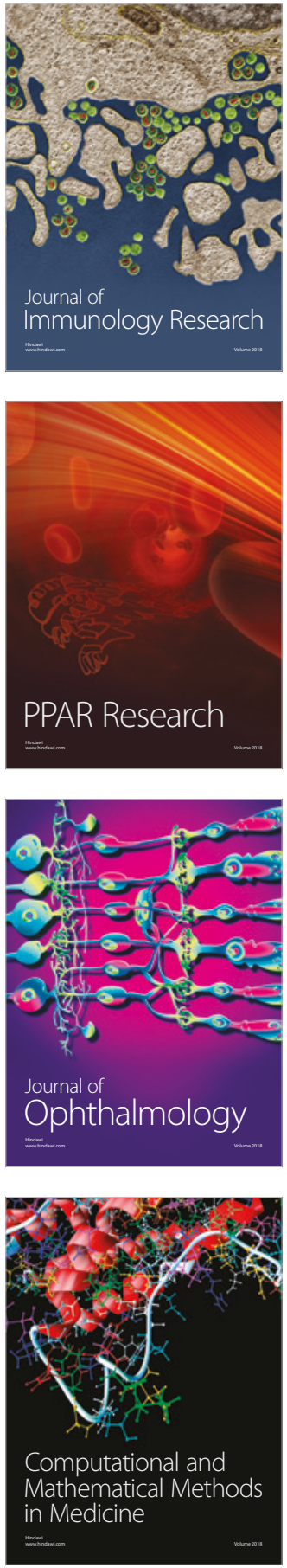

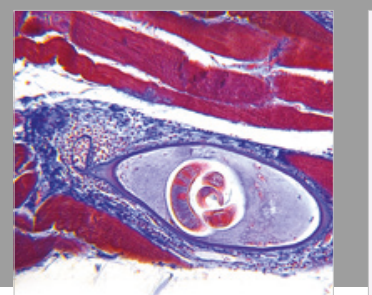

Gastroenterology Research and Practice

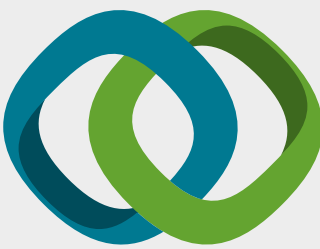

\section{Hindawi}

Submit your manuscripts at

www.hindawi.com
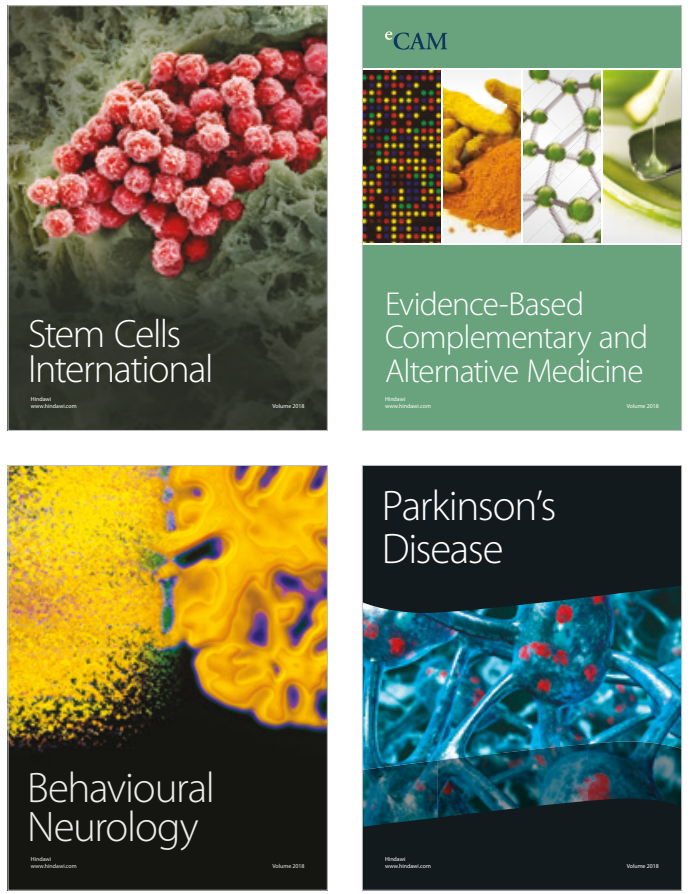

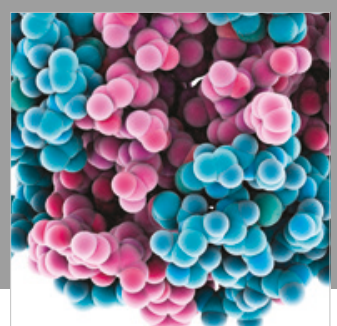

ournal of

Diabetes Research

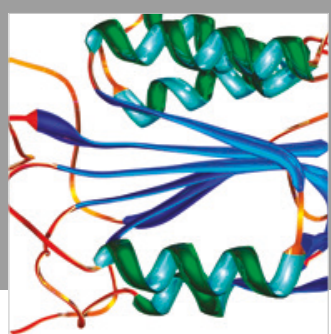

Disease Markers
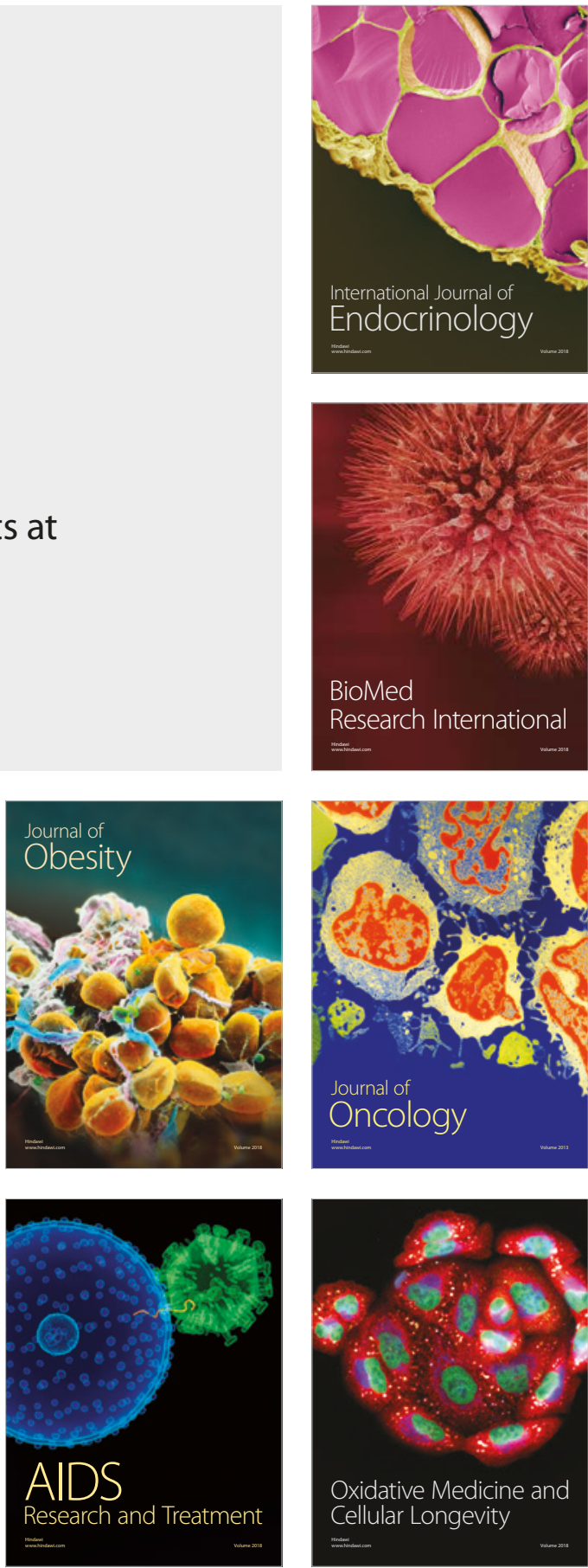